\title{
Megacolon: an unusual presentation of malrotation
}

\author{
M. Ayas, D. H. Teitelbaum, N. Uitvlugt, A. G. Coran, and A. D. Olson
}

Departments of Pediatrics and Surgery, Section of Pediatric Surgery, University of Michigan Medical School and C. S. Mott Children's Hospital, Ann Arbor, Michigan, USA

Accepted 4 January 1994

\begin{abstract}
This report describes a 9-year-old boy with a highly unusual variant of malrotation: massive colonic distention secondary to peritoneal bands and a localized volvulus. The presentation and treatment are presented.
\end{abstract}

Key words: Malrotation - Megacolon - Colonic volvulus

\section{Introduction}

Malrotation, or non-rotation of the gastrointestinal (GI) tract, can be manifested by bilious emesis, abdominal pain, and volvulus. Errors in the complex embryologic rotation of the large and small bowel can produce a multitude of rotational anomalies [1]. This report describes a patient who presented with massive colonic distention due to a variant of rotation not previously described in the surgical literature. The purpose is to alert pediatricians and surgeons of a unique radiologic and clinical presentation of malrotation.

\section{Case report}

A 9-year-old male presented to the C. S. Mott Children's Hospital with the complaint of

Correspondence to: D. H. Teitelbaum, Section of Pediatric Surgery, Mott Children's Hospital, F3970 Box 0245, Ann Arbor, Michigan 48109, USA

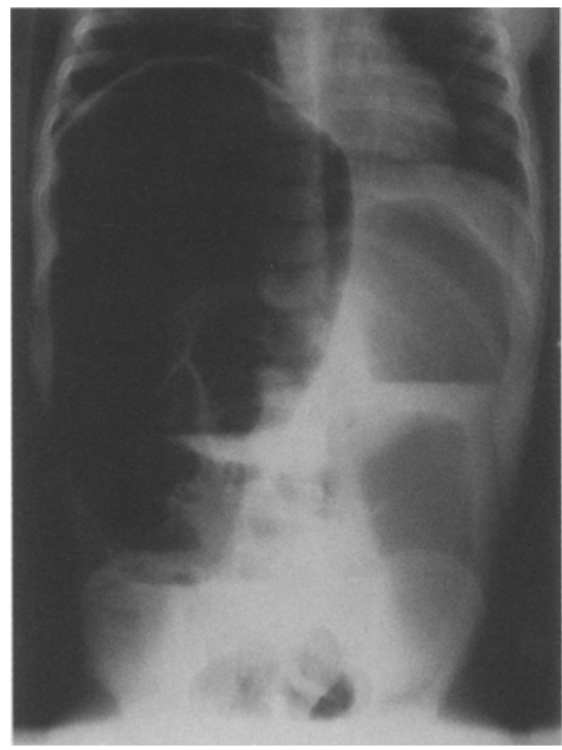

Fig. 1. Abdominal radiograph showing dilated colonic loops

vomiting for 8 days. Emesis was accompanied by liquid diarrhea for the last 3 days. Five days prior to admission he began to complain of generalized abdominal pain, which progressively increased. Two days before he presented, he started to vomit bilious material and became increasingly listless, with poor oral intake. There was no previous history of fever, blood in the stool, or vomiting. His medical history consisted of constipation and irritable bowel syndrome diagnosed 2 years prior to admission, which was treated with metamucil and a high-fiber diet. His parents reported that he had had intermittent distention of his abdomen throughout the last 3 years.

On physical examination the abdomen was markedly distended, tympanitic to percussion, and tender throughout. No hepatosplenomegaly was found, and the bowel sounds were diminished. Rectal examination showed normal stool, which was hematest negative. The

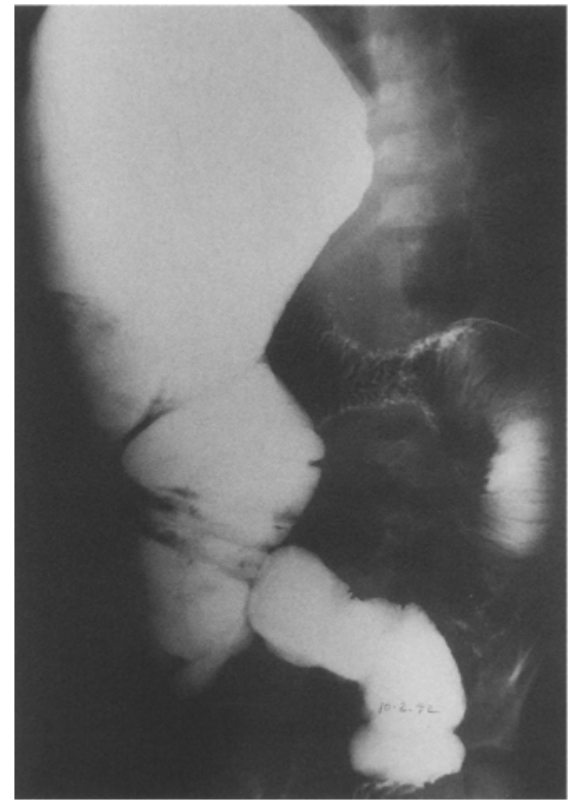

Fig. 2. Barium enema illustrates partial obstruction of transverse colon with markedly dilated proximal colon tapering into normalsized descending colon

initial laboratory findings were as follows: $\mathrm{Na}$ $137 \mathrm{mEg} / \mathrm{l} ; \mathrm{K} 4.6 \mathrm{mEgl} / 1 ; \mathrm{Cl} 103 \mathrm{mEg} / 1 ; \mathrm{CO}_{2}$ $22 \mathrm{mEg} / \mathrm{l}$; urea nitrogen $8 \mathrm{mg} / \mathrm{dl}$; creatinine $0.6 \mathrm{mg} / \mathrm{dl}$; Ca $9.1 \mathrm{mg} / \mathrm{dl}$; phosphorus $4.4 \mathrm{mg} /$ $\mathrm{dl}$; aspartate aminotransferase $14 \mathrm{U} / \mathrm{l}$; alanine aminotransferase $20 \mathrm{U} /$; lactate dehydrogenase $16 \mathrm{U} / \mathrm{l}$; alkaline phosphatase $112 \mathrm{U} / \mathrm{l}$; White blood cell count $10.8 \mathrm{~mm}^{3}$; hemoglobin $11.2 \mathrm{~g} / \mathrm{dl}$; hematocrit $33.5 \%$; amylase $34 \mathrm{U} /$; lipase $19 \mathrm{U} / \mathrm{l}$; and sedimentation rate $5 \mathrm{~mm} / \mathrm{h}$.

Abdominal radiographs showed massively dilated bowel loops in the right and left upper quadrants consistent with the right and transverse colon (Fig. 1). A diagnosis of colonic volvulus was considered and colonoscopy was performed, which showed that the colon was 


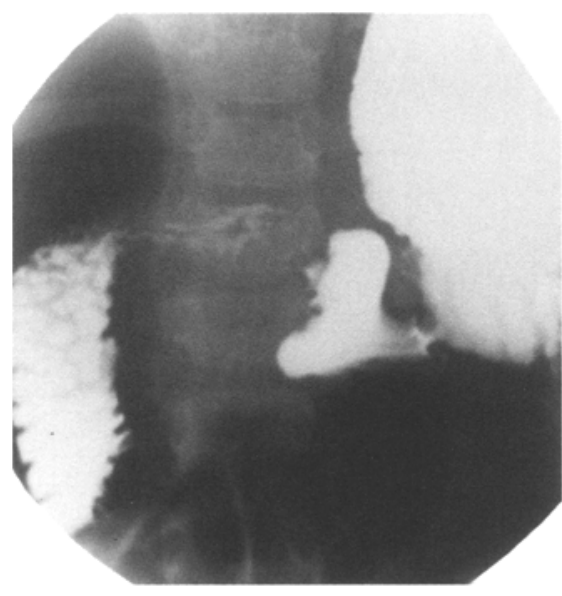

Fig. 3. Upper gastrointestinal series shows abnormal rotation of duodenum, with duodenojejunal junction inferior and to right of normal location

partially obstructed at the splenic flexure and in the mid-transverse region; marked dilatation was noted proximal to the sites of obstruction. A decompressing tube was placed by colonoscopy in the mid-transverse colon; repeat abdominal radiographs showed resolution of the dilated segment. The tube was removed 2 days later and the colonic distention recurred. Colonic biopsies showed mild, nonspecific inflammation with ganglion cells present throughout the rectum and colon. A barium enema showed a transition at the middescending colon from a dilated transverse colon to a normal caliber distally. The colon at the hepatic flexure was enlarged to $16 \mathrm{~cm}$ in diameter (Fig. 2). The cecum appeared normal and was located in the right lower quadrant. An upper gastrointestinal series (UGI) showed a normal esophagus and stomach with no evidence of gastric outlet obstruction. The duodenal bulb was normal; the first and second portions of the duodenum were in a normal location, but the third and fourth portions were anterior and did not cross the midline. The junction of duodenum and jejunum was in the midline at the level of the 1 st lumbar vertebra and was medial, inferior, and anterior to the expected location of the ligament of Treitz. There was no evidence of obstruction, abnormal dilatation, or mucosal irregularity of the small intestine (Fig. 3).

Based on the radiologic studies, it was felt that a malrotation might be the cause of the colonic obstruction. The patient was taken to the operating room and the abdomen was entered through a transverse right upper quadrant incision. Following evisceration of the bowel, tracing the course of the intestine it was observed that the distal duodenum and proximal jejunum were compressed by peritoneal bands (Ladd's bands) between the right colon and the right upper quadrant. There was no ligament of Treitz and the duodenum was anterior to the superior mesenteric vessels. The mesentery of the transverse colon was restricted to a narrow base by these peritoneal

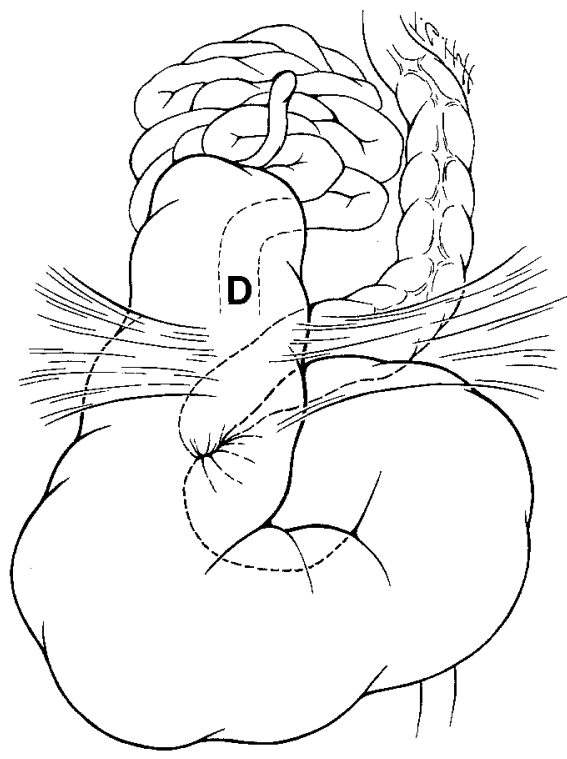

Fig. 4. Diagram of operative findings. Note non-rotation of small bowel (duodenum $(D)$ to right of midline) and horizontal peritoneal bands fixing splenic flexure, causing colon to become kinked and obstructed

bands, causing a localized volvulus of this portion of colon (Fig. 4). The transverse colon was markedly dilated and was decompressed by untwisting the large bowel. The peritoneal bands between the right colon and the right retroperitoneal region were divided, correcting the duodenal compression and narrowing of the base of the transverse colonic mesentery. The duodenum and proximal small bowel were positioned to the right of the spine and the entire colon positioned to the left. Finally, and inversion appendectomy was performed. Follow-up of the child 7 months after the operation showed him to be completely asymptomatic and thriving normally. $\mathrm{Ab}$ dominal radiographs showed normal colon caliber.

Twelve months after the child's initial operation he presented with abdominal distention. Abdominal $\mathrm{x}$-rays suggested a recurrent volvulus. He was taken to surgery where a similar volvulus of the transverse colon was discovered. He underwent a resection of the transverse and right colon with primary anastomosis. He is currently asymptomatic 5 months following this last surgery.

\section{Discussion}

Although malrotation, or non-rotation, most commonly presents with proximal obstructive symptoms within the first 2 years of life, older children and adults can present with confusing and often less specific symptoms [2]. Chronic abdominal pain, intermittent vomiting, chronic diarrhea, malabsorption, and failure to thrive have all been reported as the presenting symptoms in patients with malrotation [3]. These patients have also been misdiagnosed as having milk intolerance, food allergies, and psychogenic vomiting $[4,5]$. The chronic, nonspecific nature of the symptoms in patients with late presentation often leads to a delay in diagnosis. Spigland, et al. reported the mean delay in diagnosis to be 1.7 years in patients presenting at an older age, compared to only 5 days in infants who present early [4]. Our patient is typical of this older group. His symptoms of chronic, poorly characterized abdominal pain and abdominal distention made the diagnosis quite difficult.

Our patient's presentation was also quite unique in that megacolon as an isolated finding of malrotation has not been previously described. Malrotation has been reported in association with megacolon only secondary to Hirschsprung's disease [6]. Lassman reported the association of megacolon and malrotation, with delayed migration and degeneration of intramural ganglionic cells; this ganglionic abnormality was not found in our patient [7]. It was obvious during surgery that the dilatation of the colon was due to a partial volvulus caused by peritoneal bands. Unlike a typical midgut volvulus associated with malrotation, this one was isolated to the colon. Colonic volvulus is an unusual condition in children that usually involves the sigmoid or cecum [8] but has not been previously reported with malrotation. Colonic distention can also be seen in patients with the rare anomaly of reverse rotation of the intestine, whereby the transverse colon is located behind the superior mesenteric artery [9]. This entity is, however, clearly distinct from the one described here.

Figure 4 demonstrates the unique anatomy of this case. Ladd's bands were present in the classic locations, but also extended from the ascending and transverse colon to the left lateral abdominal wall. It was these lateral bands that apparently held the splenic flexure in place and caused it to become obstructed. In an extensive, recent review of the various anatomic patterns of malrotation, no description corresponding to our patient's findings was reported [1]. This case history illustrates how difficult the diagnosis of malrotation can be, and indicates the 
importance of both a UGI and barium enema in making the diagnosis. The barium enema in our patient showed the cecum in the proper location with no evidence of malrotation. Approximately $5 \%$ of patients with malrotation will have a normally rotated colon [4]. The UGI clearly showed the duodenal malposition diagnostic of intestinal malrotation.

In summary, we describe a case of non-rotation of the small bowel presenting with colonic obstruction. This report emphasizes that a high index of suspicion of malrotation must be maintained in any child with significant GI symptoms.

\section{References}

1. Bill AH Jr and Grauman D (1966) Rationale and technic for stabilization of mesentery in cases of nonrotation of the midgut. J Pediatr Surg 1: 127-136

2. Brandt ML, Pokorny WJ, McGill CW, and Harberg FJ (1985) Late presentation of midgut malrotation in children. Am J Surg 150: $767-771$

3. Filston HC, and Kirks DR (1982) The association of malrotation and Hirschsprung's disease. Pediatr Radiol 12: 6-10

4. Hiltunen $\mathrm{KM}$, Syrja $\mathrm{H}$, and Matitainen $\mathrm{M}$ (1992) Colonic volvulus. Eur J Surg 158: 607-611

5. Lassmann G (1987) Megacolon in thirdphase malrotation with delay of migration and degeneration of intramural ganglionic cells and nerves. Acta Neuropathol 74: 281-286

6. Powell DM, Othersen HB, and Smith CD (1989) Malrotation of the intestines in children: the effect of age on presentation and therapy. J Pediatr Surg 24: 777-780

7. Schey WL, Donalson JS, and Sty JR (1993) Malrotation of bowel: variable patterns with different surgical considerations. J Pediatr Surg 28: 96-101

8. Spigland N, Brandt ML, and Yazbeck S (1990) Malrotation presenting beyond the neonatal period. J Pediatr Surg 25: 1139 1142

9. Wang CA and Welch CE (1963) Anomalies of intestinal rotation in adolescents and children. Surgery 54: 839-855 